\title{
Comprehensive genomic and prognostic analysis of the IL-17 family genes in lung cancer
}

\author{
TINGTING LIAO $^{1 *}$, JINSHUO FAN ${ }^{1 *}$, ZHILEI LV $^{1 *}$, JUANJUAN XU $^{1}$, FENG WU $^{1}$, GUANGHAI YANG $^{2}$, \\ QI HUANG ${ }^{1}$, MENGFEI GUO ${ }^{1}$, GUORONG HU ${ }^{1}$, MEI ZHOU ${ }^{1}$, LIMIN DUAN ${ }^{1}$, SUFEI WANG ${ }^{1}$ and YANG JIN ${ }^{1}$ \\ ${ }^{1}$ Key Laboratory of Respiratory Diseases of The Ministry of Health, Department of Respiratory and Critical Care Medicine; \\ ${ }^{2}$ Department of Thoracic Surgery, Union Hospital, Tongji Medical College, Huazhong University of Science \\ and Technology, Wuhan, Hubei 430022, P.R. China
}

Received September 22, 2018; Accepted April 10, 2019

DOI: $10.3892 / \mathrm{mmr} .2019 .10164$

\begin{abstract}
The six members of the interleukin (IL)-17 gene family (IL-17A-F) have been identified in various types of cancer. Although lung cancer is the leading cause of cancer-related death worldwide and IL-17A was found to play a critical role in lung cancer, there is little knowledge concerning the association between the other five members of the IL-17 family and lung cancer. The genetic mutations and expression of IL-17 family members were investigated using the Catalogue of Somatic Mutations in Cancer (COSMIC), Oncomine, and cBio Cancer Genomics Portal (cBioPortal) databases. Prognostic values and interaction networks of the members were assessed by the Kaplan-Meier plotter, Search Tool for the Retrieval of Interacting Genes (STRING) database and FunRich software. The results found that, across 5,238 lung cancer patients in the cBioPortal, the results of IL-17 family gene alteration frequencies and types showed that IL-17A, IL-25 and IL-17F exhibited higher alteration frequencies $(2,2.1$ and $1.9 \%$, respectively), and gene amplification accounted for the majority of changes. IL-17B, IL-17C and IL-17D exhibited lower alteration frequencies $(0.8,1.1$ and $1.1 \%$, respectively), and deep deletion accounted for the majority of changes. The rates of point mutations in IL-17A through IL-17F family genes in lung cancer were $0.66,0.18$, $0.13,0.09,0.27$ and $0.44 \%$ in the COSMIC database. Within the Oncomine database, five datasets showed that IL-17D was significantly decreased in lung cancer, while no dataset showed a significant difference in the expression of IL-17A,
\end{abstract}

Correspondence to: Dr Yang Jin, Key Laboratory of Respiratory Diseases of the Ministry of Health, Department of Respiratory and Critical Care Medicine, Union Hospital, Tongji Medical College, Huazhong University of Science and Technology, 1277 Jiefang Avenue, Wuhan, Hubei 430022, P.R. China

E-mail:whuhjy@126.com

*Contributed equally

Key words: lung neoplasms, interleukin-17, gene regulatory networks
IL-17B, IL-17C, IL-25 or IL17-F between lung cancer and normal controls. The frequencies of IL-17A, IL-17B and IL-17C mRNA upregulation in lung squamous cell carcinoma were lower than those in lung adenocarcinoma $(2.7,1.9$ and $2.1 \%$, respectively), whereas the frequencies of IL-17D, IL-25 and IL-17F mRNA upregulation were higher in lung squamous cell carcinoma than those in lung adenocarcinoma (3, 6 and $6 \%$, respectively). IL-17A and IL-17B were unrelated to overall survival ( $\mathrm{p}=0.11 ; \mathrm{P}=0.17$ ), whereas IL-17C, IL-17D, IL-25 and IL-17F influenced prognosis $(\mathrm{P}=0.0023, \mathrm{P}=0.0059, \mathrm{P}=0.039$ and $\mathrm{P}=0.0017$, respectively) according to the Kaplan-Meier plotter. Moreover, the expression level of IL-17C was the highest in lung tissues, and IL-17 family genes mainly participate in the 'IFN- $\gamma$ pathway' according to the STRING database and Funrich software. In conclusion, we performed the first comprehensive investigation of the IL-17 gene family in lung cancer, including gene mutation, mRNA expression levels, prognostic values and network pathways. Our results revealed that IL-17 family gene mutation rates were in general low and that amplification and deep deletion were the main mutation type. The expression and function of IL-17A and IL-17B in lung cancer are still not fully elucidated and warrant research with larger sample sizes. IL-17D was significantly decreased in lung cancer and was correlated with better OS. Studies of IL-17C-F in lung cancer are limited. Further experimental studies on the association between IL-17D and lung cancer progression are needed to identify more effective therapeutic targets for lung cancer.

\section{Introduction}

Lung cancer is the leading cause of cancer-related death worldwide. Despite improvements in treatment, the overall 5-year survival of lung cancer remains less than $18 \%$ in the United States $(1,2)$, and the age-standardised 5-year net survival is in the range of $10-20 \%$ in most countries (2). Therefore, optimal therapies for lung cancer are urgently needed, the development of which requires extensive knowledge of the aetiology of lung cancer.

Interleukin (IL)-17 has been implicated in various cancers and is regarded as a double-edged sword in lung cancer (3). The greatest homogeneity is between IL-17A and IL-17F, 
which, together with their producing cells, have been implicated in multiple types of cancer. IL-17 is generally referred to as IL-17A in the literature. Moreover, most studies have reported that the expression of IL-17A is positively correlated with tumour growth (4-7), while various investigations have shown the opposite result (8). For example, IL-17A produced by tumour-infiltrating immune cells was found to promote cancer cell growth through an IL-6/signal transducer and activator of transcription 3 (STAT3) pathway (7), and transfection with IL-17A was found to promote hepatocellular carcinoma (HCC) tumour growth via protein kinase B (AKT)-dependent activation of IL-6/Janus kinase 2 (JAK2)/STAT3 signalling (9). However, a low level of intratumoural IL-17A expression was found to be indicative of a poor prognosis (10).

However, other members of the IL-17 family have not been well investigated for their potential roles in cancer development. The IL-17 family includes IL-17A through IL-17F and their cognate receptors, IL-17RA to IL-17RE. IL-17A was first cloned and initially named cytotoxic $\mathrm{T}$ lymphocyte-associated antigen 8 (CTLA-8) in 1993. A decade later, IL-17A was found to be a distinctive feature of Th17 cells, as it was not found in Th1 and Th2 cells. The other five family members were discovered in quick succession and designated as IL-17B, IL-17C, IL-17D, IL-25 (IL-17E) and IL-17F.

IL-17B/IL-17RB signalling has been demonstrated to be implicated in tumour malignancies, such as breast cancer (11), pancreatic cancer (12) and gastric cancer (13).IL-17C is involved in the innate immune response of human bronchial epithelial cells (14) and mediates the recruitment of tumour-associated neutrophils with enhanced tumour growth (15). IL-17C has also been found to be upregulated in intestinal cancers and is critical for the microbiota-mediated contribution to tumour development (16). The function of IL-17D in cancer has not been well described. Some studies have shown that IL-17D is poorly expressed in cancer cells and induces tumour rejection through the recruitment of NK cells (17). IL-17E (also known as IL-25) is the most divergent member in the IL-17 family. The influence of IL-25 derived from tumour-associated fibroblasts (18), macrophages and T cells (19) on tumour progression has been explored in recent years. Studies have shown that IL-25/IL-17RB (IL-25R) signalling participates in inhibiting tumour metastasis and growth (18-20). Moreover, IL-25 has been demonstrated to bind IL-17RB through nuclear factor- $\kappa \mathrm{B}(\mathrm{NF}-\kappa \mathrm{B})$ and JAK/STAT3 pathways to promote proliferation and nourish cancer stem cells in hepatocellular carcinoma (21). IL-17F, together with IL-17A, IL-25, and their receptors, has been described to be elevated in benign prostatic hyperplasia and prostate cancer (22). As mentioned above, IL-17F is the most homologous with IL-17A but lacks the same contributions to biological and physiological processes. Unlike the double-edged sword role of IL-17A in cancer (3), there is little clinical evidence illustrating the role of IL-17F in cancer, except that it has been shown to be a negative modulator that suppressed tumour angiogenesis in hepatocellular carcinoma in an animal model (23) and is a potential diagnostic biomarker when combined with vascular endothelial growth factor (VEGF) in oral squamous cell carcinoma (24).

In summary, every member of the IL-17 family has been identified to play critical roles in cancer, with the main focus on IL-17A and the interstitial cells that produce IL-17A in the tumour microenvironment. In this study, the expression and genetic alterations in IL-17 family members were investigated through the Catalogue of Somatic Mutations in Cancer (COSMIC), Oncomine and cBioPortal databases. The prognostic value and interaction network were then analysed by the Kaplan-Meier plotter and FunRich software.

\section{Materials and methods}

COSMIC analysis. The COSMIC database (https://cancer. sanger.ac.uk/cosmic) (25), an online resource providing gene mutation information, is the world's largest and most comprehensive resource for exploring the impact of somatic mutations in human cancer. Primary access to COSMIC is via the search box in the left side panel, which accepts multiple parameters including gene names, disease descriptions, mutation syntax and stable COSMIC IDs. Full mutation distribution across all tissues and cancer diseases for the IL-17 family were acquired by typing a gene name in the search bar. After clicking on 'lung cancer', we obtained mutation information for the IL17 family in lung cancer.

ONCOMINE analysis. ONCOMINE gene expression array datasets (www.oncomine.org) (26) is a cancer microarray database and web-based data-mining platform aimed at facilitating discovery from genome-wide expression analyses and comparing the transcriptome data in various types of cancer with respective normal tissues. 'IL-17A-IL-17F' were used as keywords in the Oncomine search, 'Cancer vs. Normal Analysis' was used as the primary filter, and 'Lung Cancer' was chosen as the cancer type. In this study, we selected 2.0 -fold change, $\mathrm{P}$-value $=0.05$ and top $10 \%$ gene rank as the threshold.

Kaplan-Meier plotter. Kaplan-Meier plotter (http://kmplot. com/analysis) $(27,28)$ can assess the effect of 54,675 genes on survival using 10,461 cancer samples. These samples include 5,143 breast, 1,816 ovarian, 2,437 lung and 1,065 gastric cancer patients. IL-17 family members were entered into the database to obtain Kaplan-Meier survival plots. A total of 1,926 lung cancer samples with available clinical data were split into two groups according to median expression (high vs. low expression). The two patient groups were compared by a Kaplan-Meier survival plot for overall survival (OS) using the hazard ratio (HR), 95\% confidence intervals (CIs) and log-rank $\mathrm{P}$-values. $\mathrm{P}<0.05$ was considered statistically significant.

cBioPortal. The cBio Cancer Genomics Portal (http://cbioportal.org) (29) is an open-access resource for interactive exploration of multidimensional cancer genomics datasets. The IL-17 family gene mutation and expression information in cancers were obtained according to the cBioPortal's online instructions. A mutation analysis was performed in 169 cancer studies, including mutation, amplification and deletion. Additionally, two mRNA analyses for lung cancer, namely, 'Lung Adenocarcinoma TCGA, PanCancer Atlas' and 'lung squamous cell carcinoma TCGA, PanCancer Atlas', were made available on cBioPortal, with 510 and 487 samples, respectively. 
STRING database. STRING database (Search Tool for the Retrieval of Interacting Genes; available at http://string- $d b$. org/) (30) provides uniquely comprehensive coverage and easy access to protein-protein interaction information. The common gene networks of the IL-17 family were constructed independently by importing gene symbols. We selected the interactions pertaining to Homo sapiens and showed minimum interactions with a confidence score $>0.9$. Only the interactions with a combined score $>0.4$ were considered significant.

Functional analysis. Functional enrichment analysis of the interaction proteins was performed using FunRich (http://www. funrich.org), which is an open access, standalone functional enrichment and network analysis tool (31). The functional analysis of related genes that interact with IL-17 family genes was conducted with FunRich software. The STRING interaction proteins were imported into FunRich, and significantly enriched pathways and site of expression were analysed.

Statistical analysis. Student's t-test (two-tailed) was used to compare the means between two groups. mRNA expression data are presented as fold change, and P-values $<0.05$ were considered statistically significant. Overall survival (OS) data are displayed as Kaplan-Meier plots, with P-values calculated using the log-rank test. P-values $<0.05$ were considered statistically significant

\section{Results}

IL-17 family gene mutations in lung cancer. The IL-17 family gene mutations in lung cancers were assessed using cBioPortal (29). IL-17 family genes were examined in 169 cancer studies of genetic mutations. As shown in Fig. 1A, IL-17 genetic mutations in lung adenocarcinoma (TCGA; https://tcga-data.nci.nih.gov) (32) were not the highest compared with those in neuroendocrine prostate cancer (NEPC) (Trento/Cornell/Broad 2016) (33) and breast cancer (BCCRC Xenograft) (34) but were present in $10 \%$ of the 230 cases. The IL-17 family gene mutation frequencies and types in 5,238 samples from 12 lung cancer studies are shown in Fig. 1B. IL-17A, IL-25 and IL-17F exhibited higher mutation frequencies (2, 2.1 and $1.9 \%$, respectively), and gene amplification accounted for the majority of changes. IL17B, IL17C and IL17D exhibited lower alteration frequencies $(0.8$, 1.1 and $1.1 \%$, respectively), and deep deletions accounted for the majority of changes. We also investigated the mutation frequencies of IL-17 family genes (including point mutations and copy number variation (CNV)) using the COSMIC database (COSMIC v83 released 07-Nov-17), a comprehensive resource for exploring somatic mutations in human cancer (25). The genetic point mutations of IL-17A to IL-17F family genes in lung cancer were $0.66,0.18,0.13,0.09,0.27 \%$ and $0.44 \%$, respectively. Notably, IL-25, rather than IL-17A or IL-17F, exhibited the highest CNV (1.51\%) (Table I), which was positively related to mRNA expression (Fig. 1C).

Expression of IL-17 family members in lung cancer. The expression levels of the six IL-17 family members in cancers were investigated using Oncomine (26) and cBioPortal (29). We first measured the expression levels of six IL-17 family members in 20 types of cancers and compared the expression levels to those in normal individuals. Four datasets showed significantly increased expression of IL-17A in cancers such as brain cancer, leukaemia and sarcoma, and nine datasets showed decreased expression of IL-17A in cancers such as oesophageal carcinoma, cervical cancer and pancreatic cancer. However, no dataset showed a significant difference in IL-17A expression between lung cancer and controls. Likewise, two datasets showed that IL-17B was highly expressed in brain cancer, and four datasets showed decreased IL-17B expression in breast cancer. Two datasets showed that IL-17C was overexpressed in other cancers, and five datasets showed that IL-17E was decreased in four types of cancer. Notably, five datasets showed that IL-17D was significantly decreased in lung cancer. Data on IL-17F in cancer are rare, and no results showed changes in its expression in cancer Fig. 2). Therefore, we assessed the mRNA expression of IL-17 family members in different lung cancer datasets. Table II shows that IL-17A, IL-17B, IL-17C and IL-25 mRNA overexpression was not significant in the Hou et al (35), Beer et al (36), Garber et al (37), Selamat et al (38) and Landi et al (39) lung datasets. According to the Garber et al (37), Okayama et al (40) and Hou lung datasets, IL-17D downregulation was observed in lung adenocarcinoma and squamous cell lung carcinoma compared with normal lung tissue, with a fold change $>2.0$. We also evaluated whether alterations in IL-17 family gene mRNA are associated with a specific histological type of non-small cell lung cancer (NSCLC) using cBioPortal (Fig. 3). In the TCGA PanCancer Atlas (https://gdc.cancer. gov/about-data/publications/pancanatlas) (41), 510 samples of lung adenocarcinoma and 484 samples of lung squamous cell carcinoma with mRNA data (RNA Seq V2) were investigated. An mRNA expression z-score \pm 2.0 was set as the threshold. The result showed that the IL-17A-F mRNA upregulation frequencies in lung adenocarcinoma were 4, 4, 4, 2.4, 5 and $2.5 \%$, respectively. The IL-17A, IL-17B and IL-17C mRNA upregulation frequencies in lung squamous cell carcinoma were lower than those in lung adenocarcinoma (2.7, 1.9 and $2.1 \%$, respectively), whereas the IL-17D, IL-25 and IL-17F mRNA upregulation rates were higher in lung squamous cell carcinoma (3,6 and $6 \%$, respectively).

Prognostic analysis of IL-17 family genes in lung cancer. The prognostic information of IL-17 family genes in lung cancer is freely available at http://kmplot.com/analysis (27). However, there were no significant associations of IL-17A and IL-17B expression levels with the OS of lung cancer patients (Fig. 4A and B). High IL-17C (HR 1.29 (1.09-1.52); P=0.0023) and IL-25 (HR 1.14 (1.01-1.3); P=0.039) mRNA expression levels were associated with poor OS in lung cancer patients. Conversely, higher mRNA levels of IL-17D (HR 0.79 (0.670.94); $\mathrm{P}=0.0059)$ and IL-17F (HR 0.77 (0.65-0.91); $\mathrm{P}=0.0017$ ) were associated with better long-term OS (Fig. 4C-F).

Network pathway regulation analysis of the IL-17 family. To explore the interactions of the IL-17 family and regulation in biological processes, we constructed protein-protein interaction (PPI) networks by submitting an IL-17 family gene list to the STRING data and analysed the networks using FunRich software (31). Each constructed common gene network had 

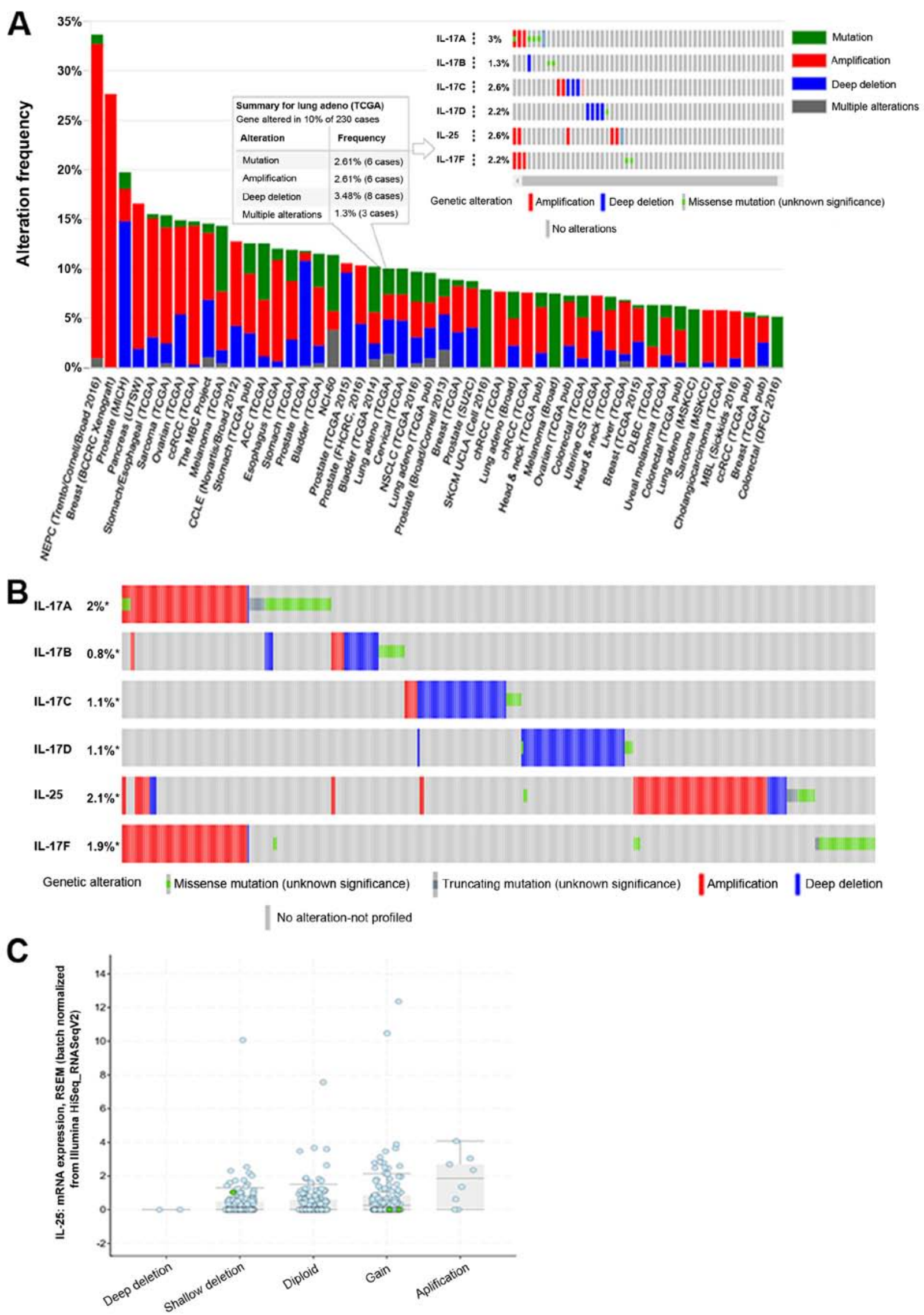

Figure 1. Analysis of IL-17 family gene mutations using the Oncomine database. (A) Gene mutation frequencies of IL-17 family members in various carcinoma types. The red bars indicate gene amplifications, blue bars are homozygous deletions, green bars are non-synonymous mutations, gray bars indicate multiple alterations. (B) IL-17 family gene mutation frequencies and types in 5,238 lung cancer samples. The red bars indicate gene amplifications, blue bars are deep deletions, green bars are missense mutations, gray bars indicate truncating mutations. (C) The correlation between mRNA expression and copy number variations (CNVs) of IL-25. IL-25 mRNA was increased in the lung cancer tissues in which IL-25 was amplified. Deep deletion, homozygously deleted; Shallow deletion, heterozygously deleted; Diploid, two alleles present; Gain, low-level gene amplification event; Amplification, high-level gene amplification event. 
31 nodes, which were considered the most highly connected protein interactions (Fig. 5). Many of the interacting proteins were also connected with molecules in other networks, probably indicating that IL-17 family members share functional associations with each other. The potential targeted genes were used for the biological pathway and site expression analysis with FunRich software. The results showed that IL-17A was significantly enriched in proteins involved in the 'IFN- $\gamma$ pathway' $(83.87 \%)$ and ' $\alpha 9 \beta 1$ integrin signalling events' (80.65\%). IL-17B was significantly enriched in 'IFN- $\gamma$ ' (83.87\%) and 'IL-23-mediated signalling events' (83.87\%). IL-17C was enriched in 'TNF receptor signalling pathway' (38.71\%) and 'IFN- $\gamma$ ' (45.16\%). IL-17D was enriched in ' $\alpha 9 \beta 1$ integrin signalling events' (51.61\%) and 'IFN- $\gamma$ ' (48.39\%). IL-25 was enriched in 'IL-23-mediated signalling events' (40\%) and 'IFN- $\gamma$ ' (43.33\%), and IL-17F was mainly enriched in 'transcription' (61.29\%) (Fig. 6A). Moreover, the analysis based on the term 'site of expression' showed that IL-17C expression levels were higher in the lung than in other family members in other sites (Fig. 6B).

\section{Discussion}

The IL-17 family, a subset of cytokines consisting of IL-17A-F, plays crucial roles in inflammation, autoimmune diseases and cancer. IL-17A and IL-17F are primarily secreted by immune cells, whereas IL-17B, IL-17C, IL-17D, and IL-25 are derived from a wide range of cells (42). Among all members, the expression and biological function of IL-17A have been widely studied in lung cancer (Table III). Initial studies have shown that increased expression of IL-17A in cancer tissue and serum were associated with poor survival of patients with lung cancer (43-47). Overexpression or exogeneous IL-17A can promote tumour growth $(48)$, angiogenesis $(49,50)$ and metastasis (51). Other studies have observed that high levels of intratumoral IL-17A expression may indicate good prognosis in gastric adenocarcinoma (10), and similar results have been obtained in oesophageal squamous cell carcinoma (52) and cervical adenocarcinoma (53). These previous studies with small cohorts had limited statistical and clinical power. Furthermore, very little is known about the expression of other IL-17 cytokines in lung cancer. Large databases such as Oncomine and TCGA provide large samples and datasets. Through the integration and analysis of massive bioinformatic data, we can avoid errors associated with small sample experimental research and increase the credibility of the research results. In the present study, the gene mutations, mRNA expression levels, prognostic values and network pathways of different IL-17 family members were investigated, aiming to find directions for further studies and potential therapeutic targets in lung cancer.

A number of studies have reported that IL-17 genetic family polymorphisms are associated with increased risk of cancer. It was demonstrated that IL-17A and IL-17F gene polymorphisms were associated with an increased risk of lung cancer (54-56), gastric cancer (57), acute myeloid leukaemia (58), and colorectal cancer (59). Furthermore, IL-17A polymorphisms may upregulate IL-17A expression (60) and are associated with clinicopathological features and tobacco smoking history in lung cancer patients (54). The relationships between the 


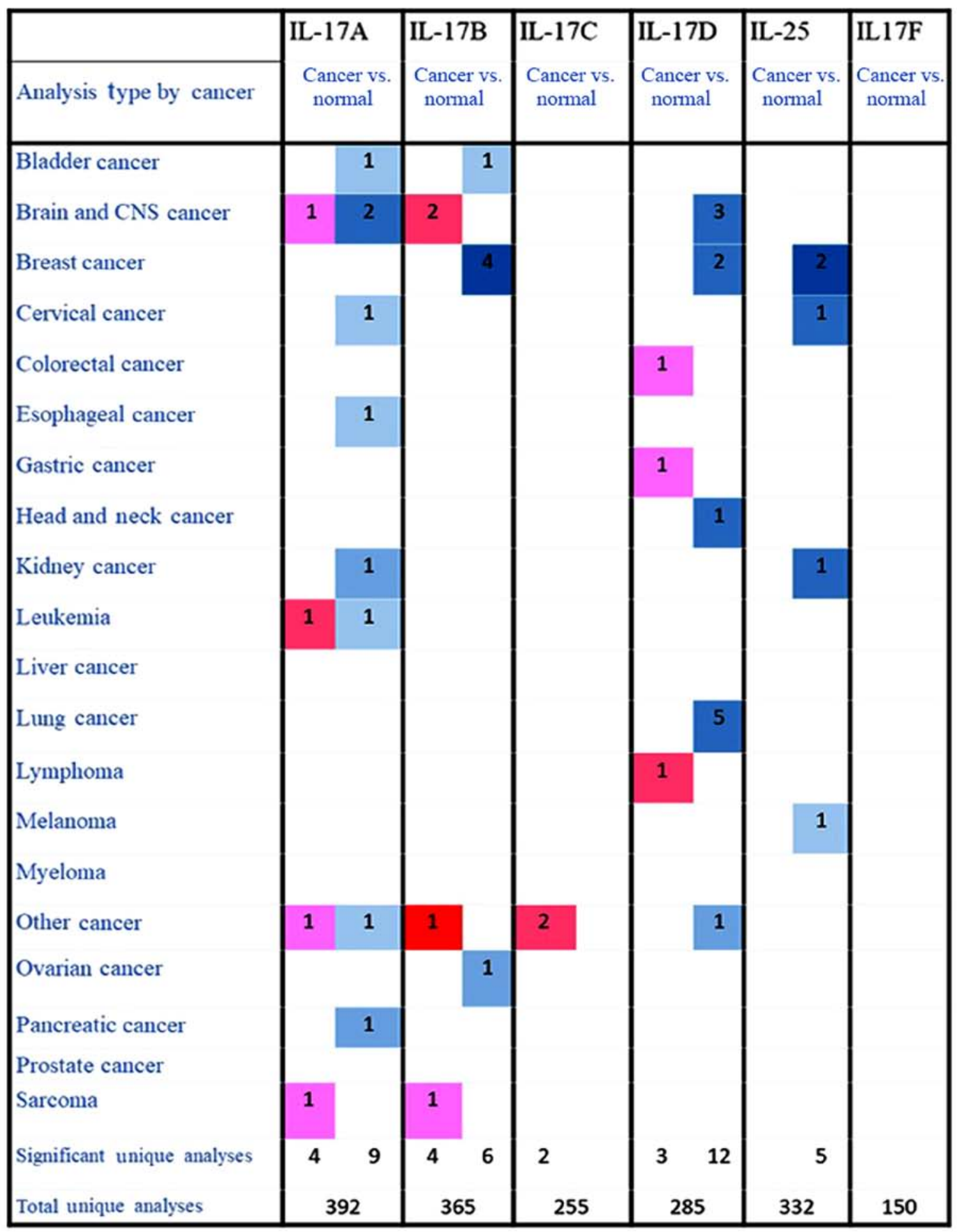

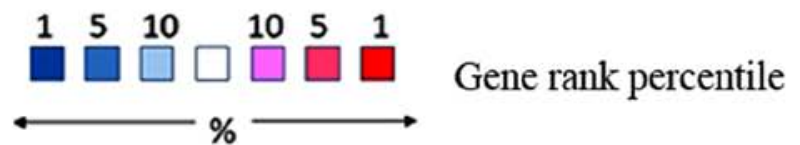

Figure 2. IL-17 family member expression status in different types of cancers with the threshold of $\mathrm{P} \leq 0.05$, fold change $\geq 2$, and gene rank $\geq$ top $10 \%$, according to the Oncomine database. The numbers in the cells represent the number of datasets that met the threshold settings. The colour indicates the gene expression trend: red represents significant overexpression and blue represents reduced expression. The depth of the colour indicates the degree of overexpression or underexpression.

genetic polymorphisms of other IL-17 family members and lung cancer susceptibility are not fully understood. In our study, the frequencies and types of alterations of IL-17 family genes were analysed through the COSMIC and cBioPortal databases. The present results revealed that IL-17 family gene mutation rates were in general low, and amplification and 
Table II. Expression status of IL-17 family at the transcriptional levels in different lung cancer datasets (Oncomine database).

\begin{tabular}{|c|c|c|c|c|c|c|}
\hline Gene & Types of lung cancer & Fold change & P-value & Sample & t-test & (Refs.) \\
\hline \multirow[t]{2}{*}{ IL-17A } & Lung adenocarcinoma & 1.143 & 0.035 & 96 & 1.848 & $(36)$ \\
\hline & Large cell lung carcinoma & 1.067 & 0.023 & 156 & 2.096 & $(35)$ \\
\hline \multirow[t]{2}{*}{ IL-17B } & Large cell lung carcinoma & 1.517 & 0.008 & 73 & 3.045 & $(37)$ \\
\hline & Squamous cell lung carcinoma & 1.148 & 0.002 & 156 & 3.114 & $(35)$ \\
\hline \multirow[t]{4}{*}{ IL-17C } & Squamous cell lung carcinoma & 1.227 & $1.77 \mathrm{E}-5$ & 156 & 4.630 & $(35)$ \\
\hline & Lung adenocarcinoma & 1.156 & $1.47 \mathrm{E}-4$ & 156 & 3.788 & $(35)$ \\
\hline & Large cell lung carcinoma & 1.132 & 0.009 & 156 & 2.502 & $(35)$ \\
\hline & Lung adenocarcinoma & 1.071 & 0.031 & 116 & 1.905 & $(38)$ \\
\hline \multirow[t]{4}{*}{ IL-17D } & Lung adenocarcinoma & -2.408 & $6.34 \mathrm{E}-5$ & 73 & -5.947 & $(37)$ \\
\hline & Lung adenocarcinoma & -2.321 & $1.01 \mathrm{E}-11$ & 246 & -10.346 & $(40)$ \\
\hline & Lung adenocarcinoma & -2.313 & $3.85 \mathrm{E}-17$ & 156 & -9.994 & $(35)$ \\
\hline & Squamous cell lung carcinoma & -2.298 & $7.56 \mathrm{E}-11$ & 156 & -7.993 & $(35)$ \\
\hline \multirow[t]{4}{*}{ IL-25 } & Lung adenocarcinoma & 1.062 & 0.018 & 156 & 2.131 & $(35)$ \\
\hline & Large Cell Lung Carcinoma & 1.049 & 0.104 & 156 & 1.292 & $(35)$ \\
\hline & Squamous cell lung carcinoma & 1.092 & 0.002 & 156 & 3.073 & $(35)$ \\
\hline & Lung adenocarcinoma & 1.033 & 0.082 & 107 & 1.405 & $(39)$ \\
\hline IL-17F & Lung adenocarcinoma & -1.002 & 0.558 & 116 & -0.146 & $(38)$ \\
\hline
\end{tabular}

A

510 patients with lung adenocarcinoma

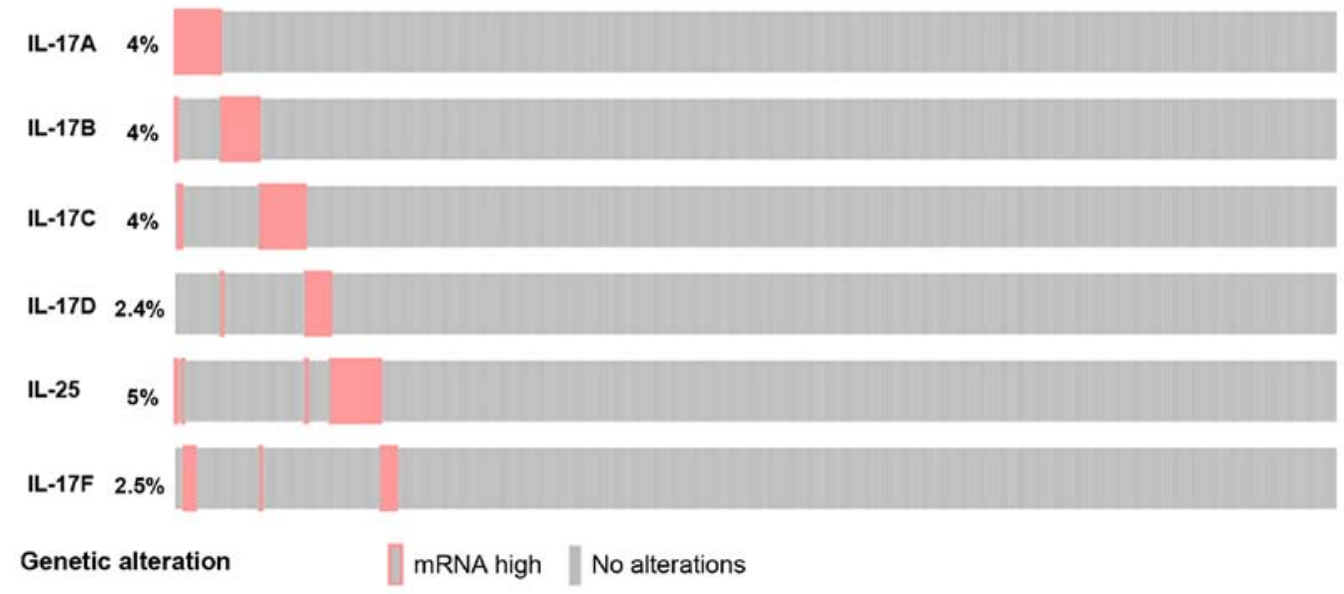

B $\quad 484$ patients with lung squamous carcinoma

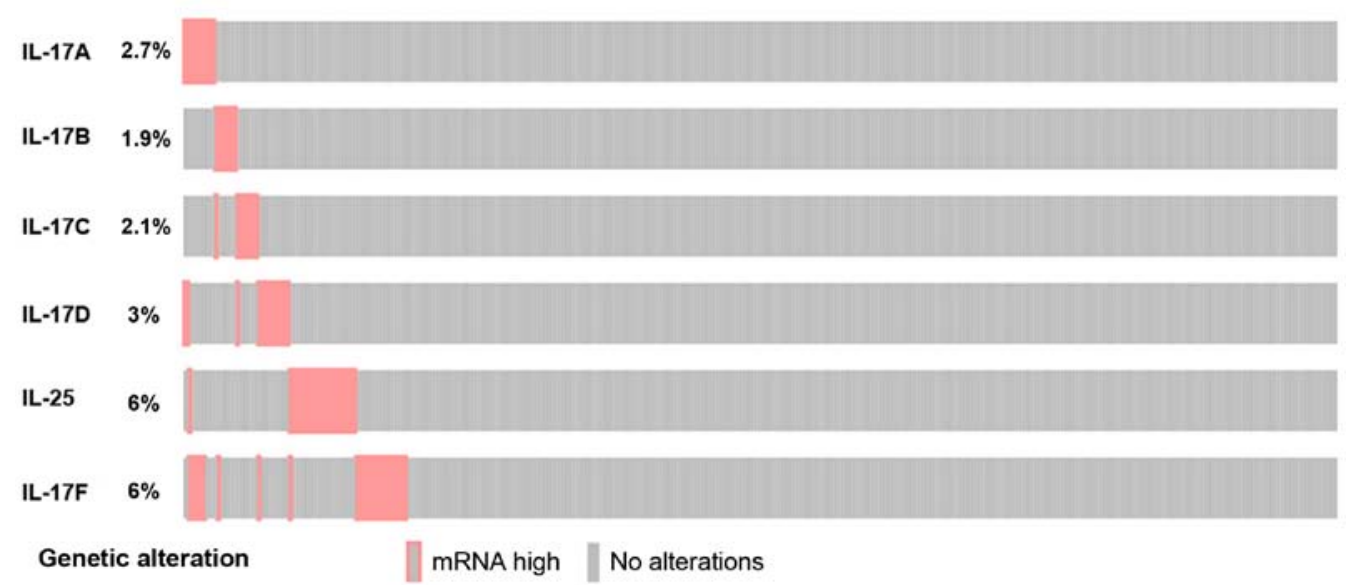

Figure 3. IL-17 family gene mRNA alterations in lung adenocarcinoma and lung squamous cell carcinoma. (A) Dysregulation of IL-17 family mRNA levels in 510 patients with lung adenocarcinoma. (B) Dysregulation of IL-17 family mRNA levels in 484 patients with lung squamous cell carcinoma. Red bars indicate mRNA upregulation, gray bars indicate no alterations. 
A

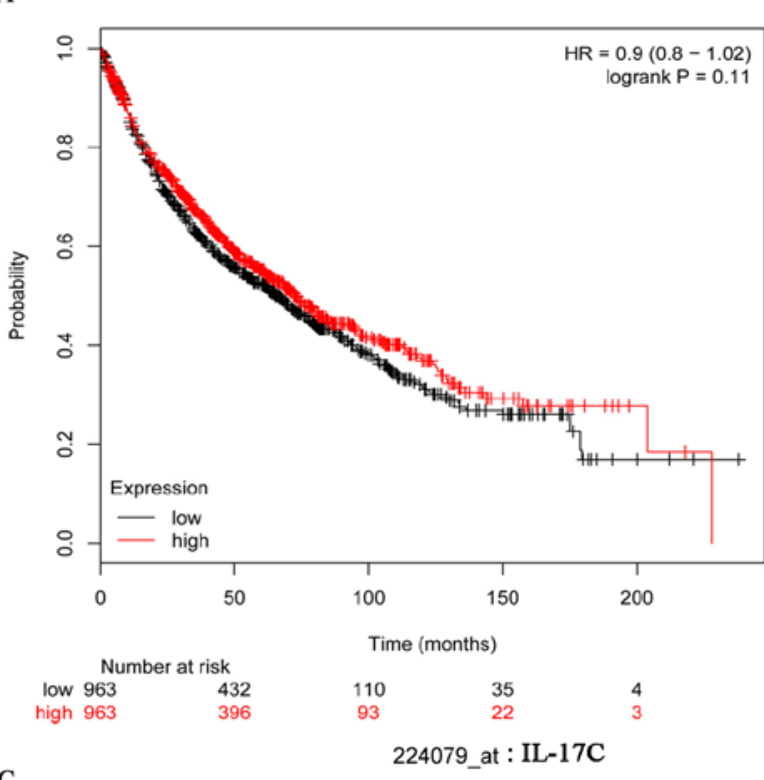

C

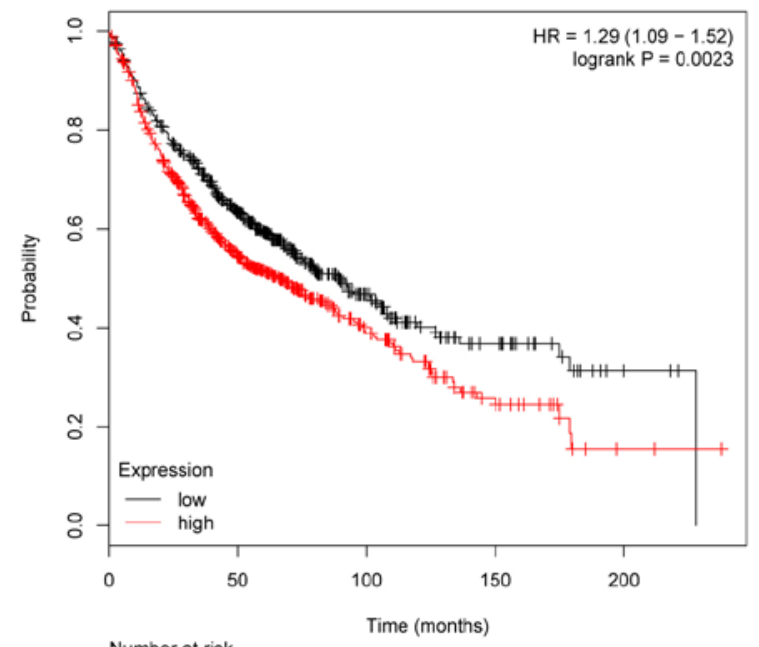

Number at risk

$\begin{array}{rr}\text { low } 594 & 320 \\ \text { high } 551 & 226\end{array}$

$\mathrm{E}$

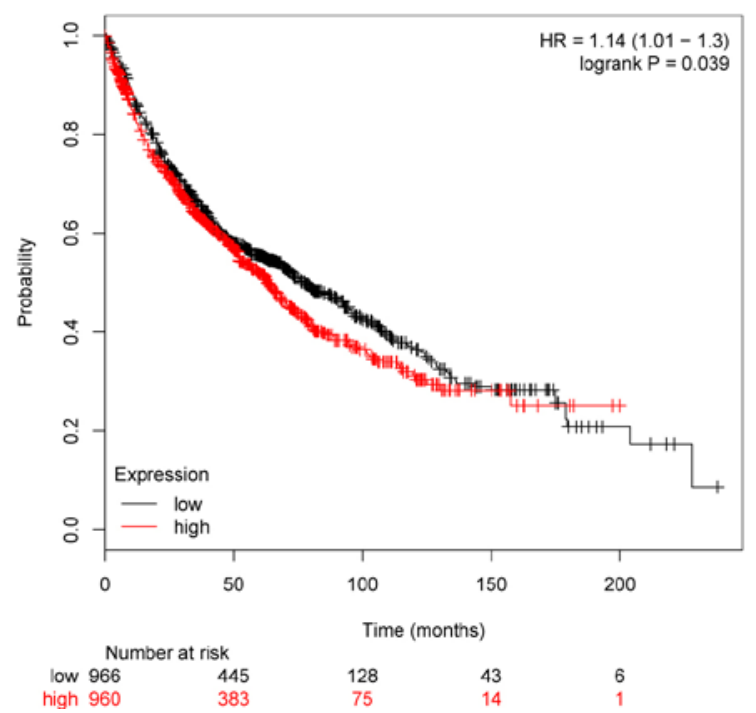

B

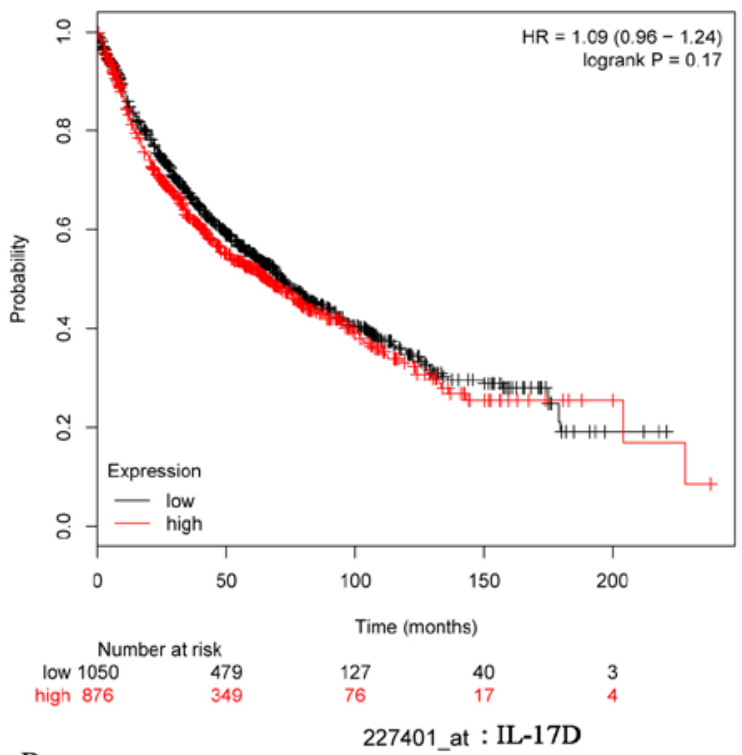

D

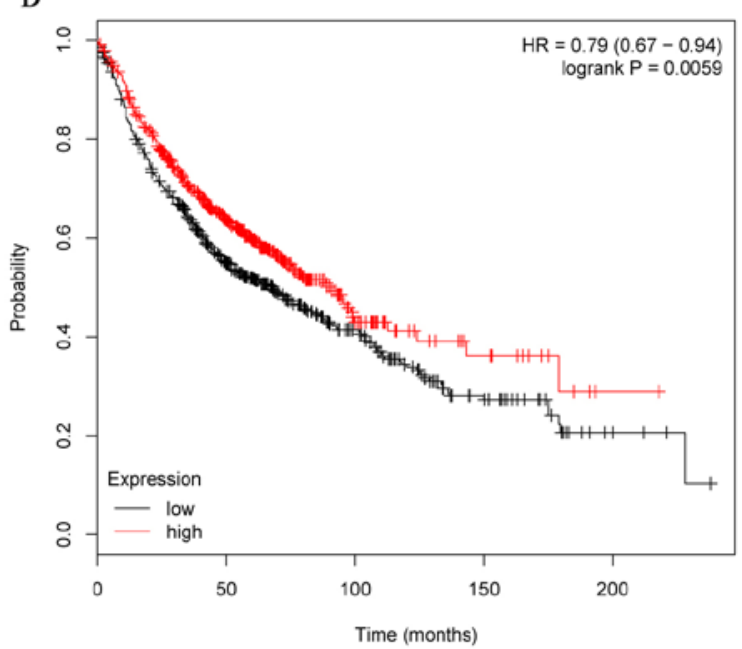

Number at risk

$\begin{array}{lllll}\text { low } 579 & 272 & 97 & 34 & 5 \\ \text { high } 566 & 274 & 42 & 12 & 1\end{array}$

234408_at: IL-17F

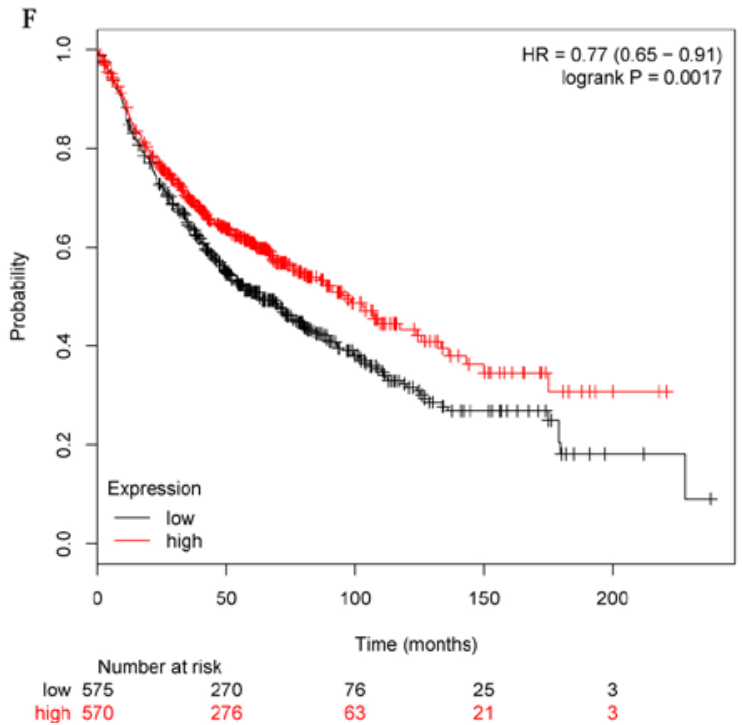

Figure 4. The prognostic value of mRNA levels of IL-17 family members in lung cancer patients (OS in Kaplan-Meier plotter). (A) Prognostic value of IL-17A expression. Affymetrix ID for IL-17A:208402_at. (B) Prognostic value of IL-17B expression. Affymetrix ID for IL-17B:220273_at. (C) Prognostic value of IL-17C expression. Affymetrix ID for IL-17C:224079_at. (D) Prognostic value of IL-17D expression. Affymetrix ID for IL-17D:227401_at. (E) Prognostic value of IL-25 expression. Affymetrix ID for IL-17E:220971_at. (F) Prognostic value of IL-17F expression. Affymetrix ID for IL-17F:234408_at. OS, overall survival. 
A

$$
\text { IL-17A }
$$

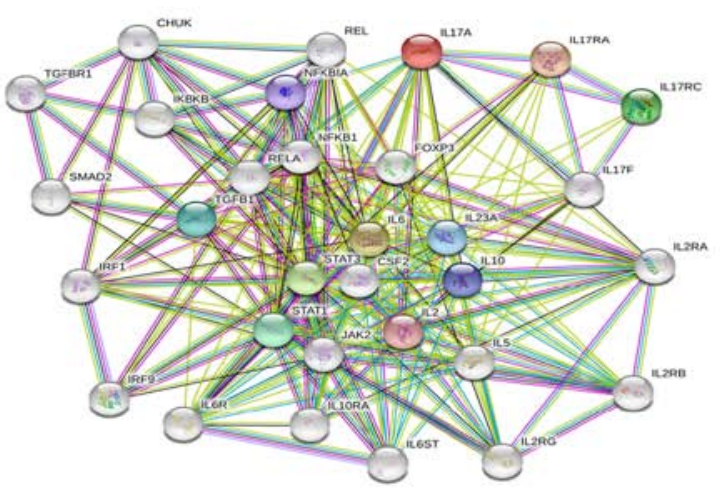

C

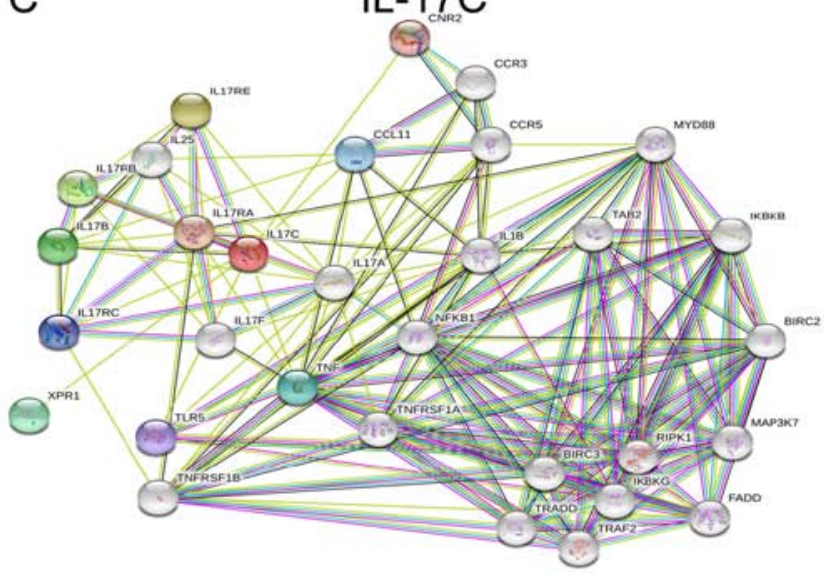

E

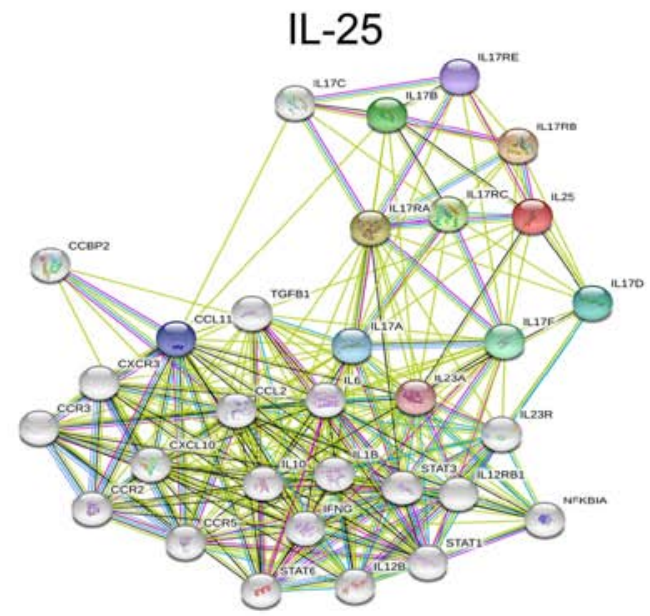

B

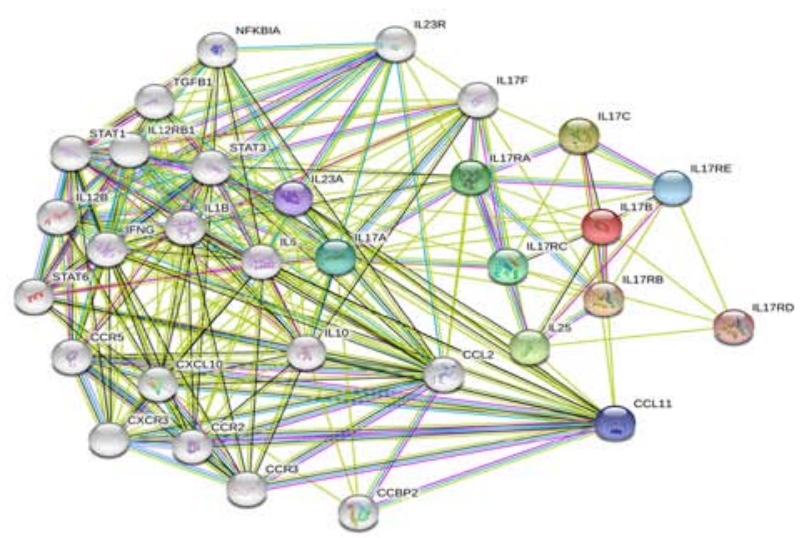

D
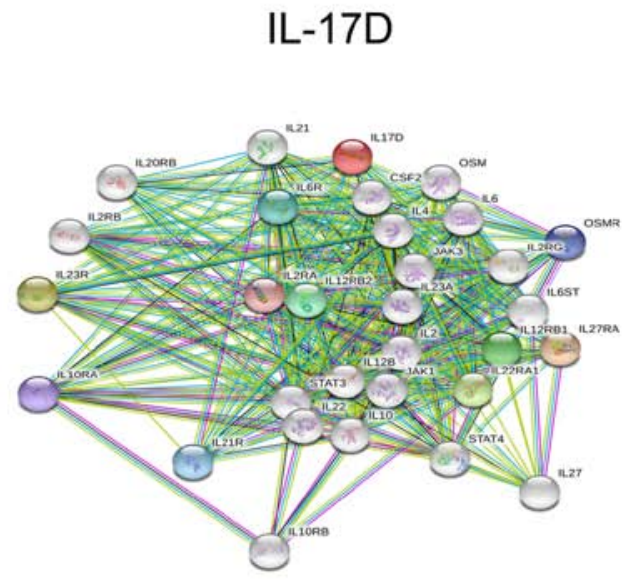

F

\section{IL-17F}

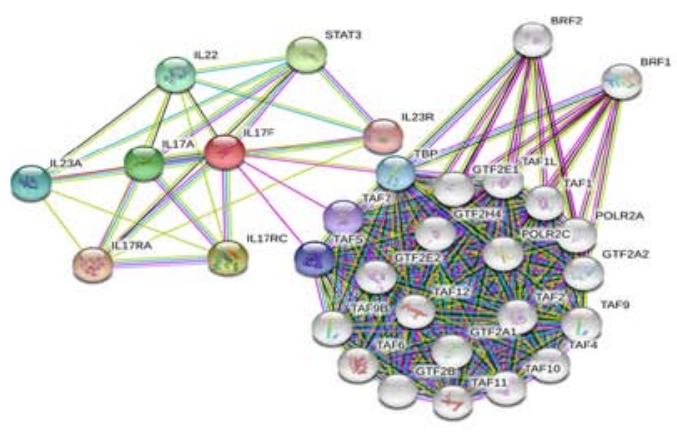

Figure 5. IL-17 family protein-protein interaction network derived from STRING database. In a biological network, a node is any biological molecule and an edge indicates the interaction between two nodes. (A) Interaction network of IL-17A. (B) Interaction network of IL17-B (C) Interaction network of IL-17C. (D) Interaction network of IL-17D. (E) Interaction network of IL-25. (F) Interaction network of IL-17F.

deep deletion were the main mutation type. The incidence of $\mathrm{CNV}$ was found to be higher than that of point mutations, and IL-17E exhibited the highest CNV, which was positively related to mRNA expression in lung cancer. IL-17E, which had the highest CNV in lung cancer, represents a promising potential oncogene in lung cancer that warrants further clinical and experimental investigation in the future.

Among the IL-17 family, IL-17A, IL-17B, IL17C and IL-17F were reported to have promoting effects on lung cancer development. In the Oncomine database, our results revealed that five datasets showed significantly decreased IL-17D expression in lung cancer, and no dataset showed a significant difference in the expression of IL-17A, IL-17B, IL-17C, IL-25 or IL17-F between lung cancer and controls. In other lung cancer datasets, IL-17A, IL-17B, IL-17C and IL-25 mRNA levels were upregulated, but the increase was small. IL-17D mRNA levels were downregulated with a fold change $>2.0$ in NSCLC. Analysis of the cBioPortal database revealed that IL-17 family mRNA alteration frequencies may be associated with specific histological types of NSCLC. IL-17A, IL-17B 
Table III. Studies of the IL-17 family genes in lung cancer.

\begin{tabular}{llcll}
\hline Gene & \multicolumn{1}{c}{ Alteration } & Effects & \multicolumn{1}{c}{ Mechanism } & $($ Refs.) \\
\hline IL-17A & Gene polymorphisms & + & Tumourigenesis & $(54-56,60)$ \\
IL-17A & High expression & + & Poor survival & $(43-47,62)$ \\
IL-17A & High expression & + & Tumourigenesis & $(63,64)$ \\
IL-17A & High expression & -- & Proliferation & $(64,65)$ \\
IL-17A & High expression & + & Proliferation & $(66)$ \\
IL-17A & High expression & + & Apoptosis & $(66)$ \\
IL-17A & High expression & + & Angiogenesis & $(48-50,64,65)$ \\
IL-17A & High expression & + & Lymphangiogenesis & $(67)$ \\
IL-17A & High expression & + & Metastasis & $(48,51,63,68-70)$ \\
IL-17A & High expression & + & Recruit MDSCs & $(71)$ \\
IL-17A & High expression & + & Recruit TAN & $(5)$ \\
IL-17A & High expression & + & Recruit macrophages & $(72)$ \\
IL-17B & High expression & + & Metastasis & $(73)$ \\
IL-17C & High expression & + & Recruit TAN & $(15)$ \\
IL-17F & Gene polymorphisms & + & Tumourigenesis & $(54)$ \\
IL-17F & High expression & + & Tumourigenesis & $(74)$
\end{tabular}

'+' means pro-tumor; '--'means on effects; MDSCs, myeloid-derived suppressor cells; TAN, tumor-associated neutrophils.

A Biological pathway for IL-17A, IL-17B, IL-17C, IL-17D, IL-25, IL-17F

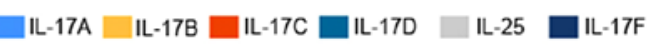

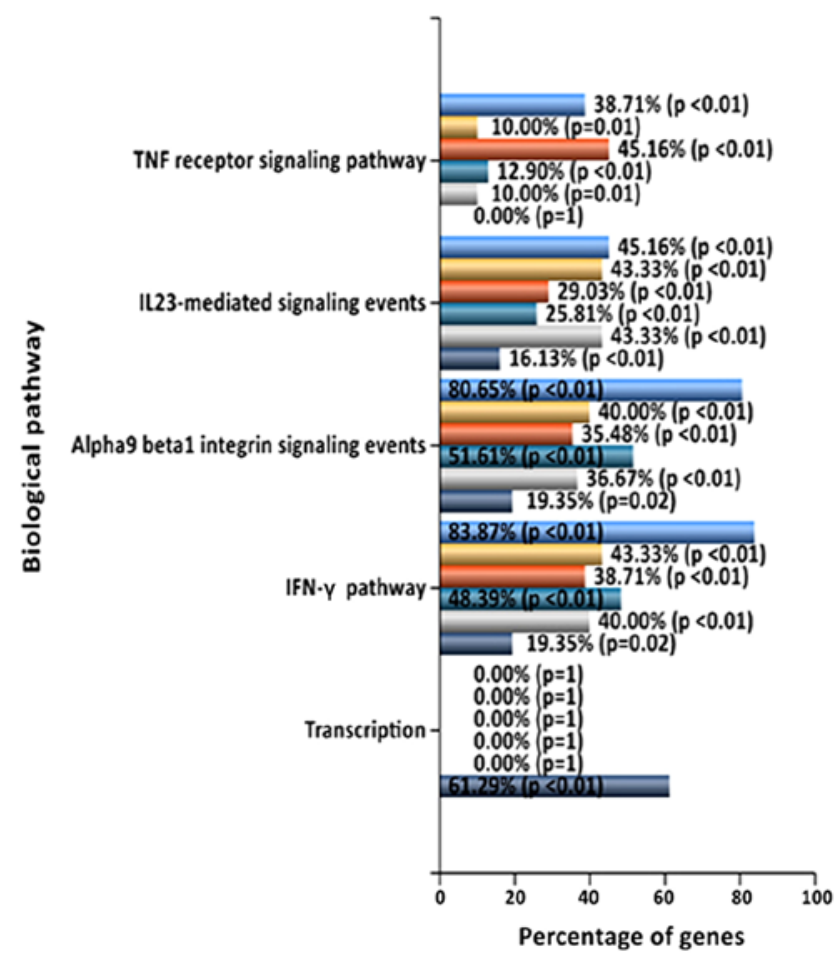

B Site of expression for IL-17A, IL-17B, IL-17C, IL-17D, IL-25, IL-17F $\square$ IL-17A $\square$ IL-17B $\square$ IL-17C $\square$ IL-17D $\square$ IL-25 $\square$ IL-17F

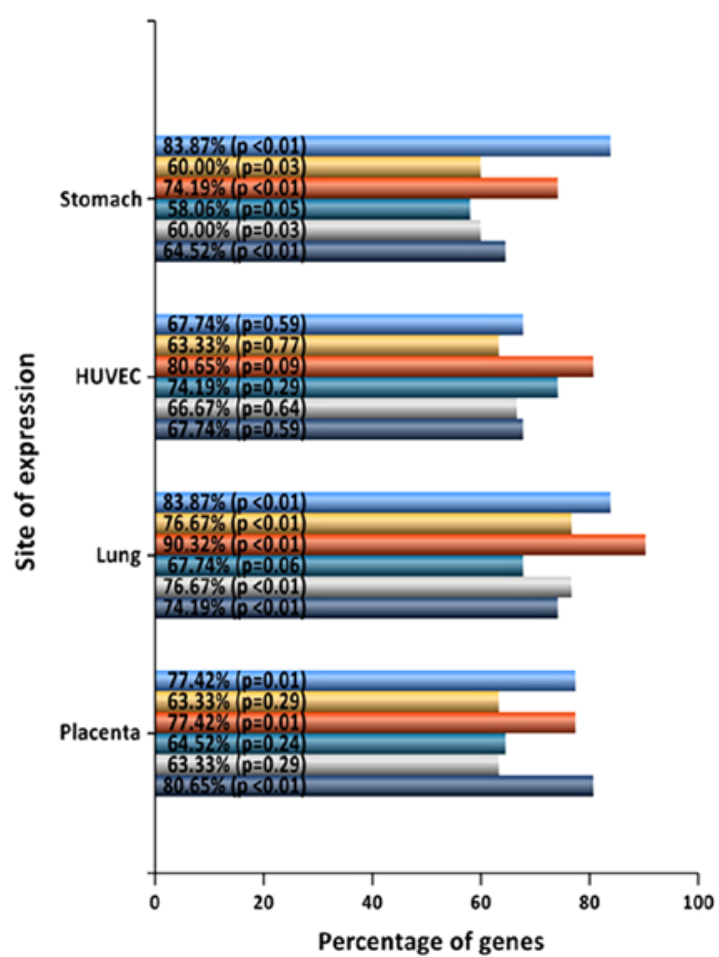

Figure 6. FunRich analysis. (A) The possible biological pathways and (B) site of expression of IL-17 family genes as determined by FunRich. FunRich is a Functional Enrichment tool. (A) IL-17 family genes were significantly enriched in proteins involved in the 'IFN- $\gamma$ pathway' $(83.87 \%$, P $<0.01)$, 'Alpha9beta1 ( $\alpha 9 \beta 1)$ integrin signalling events' (80.65\%, $\mathrm{P}<0.01)$, 'Transcription' (61.29\%, $\mathrm{P}<0.01)$, 'TNF receptor signalling pathway' $(45.16 \%, \mathrm{P}<0.01)$, and 'IL-23-mediated signalling events' $(45.16 \%, \mathrm{P}<0.01)$. (B) IL-17A-F expression levels in the lung were 83.87, 76.67, 90.32, 67.74, 76.67 and 74.19\%, respectively.

and IL-17C mRNA upregulation frequencies were lower in lung squamous cell carcinoma than in lung adenocarcinoma. IL-17D, IL-25 and IL-17F mRNA upregulation rates were higher in lung squamous cell carcinoma than in lung adenocarcinoma. However, the prognostic information indicated that IL-17A and IL-17B showed no effect on the OS of patients 
with lung cancer. High mRNA expression levels of IL-17C and IL-25 were associated with poor OS in lung cancer patients; conversely, high mRNA levels of IL-17D and IL-17F were correlated with better OS.

Analysis of the interaction network and regulation of IL-17 family genes revealed that the biological pathways of IL-17D and IL-17A overlapped. Moreover, all IL-17 family genes, except IL-17F, mainly participated in the 'IFN- $\gamma$ pathway'. Th1-associated cytokines (IFN- $\gamma$ ) have been suggested to augment anti-tumour responses by positively modulating cancer-directed immune effectors, such as dendritic cells (DCs), T cells and NK cells (61). This information suggests that the relationship between IL-17 family genes and the lung cancer immune microenvironment should be studied in-depth. Based on our results, we can conclude that IL-17 family gene mutation rates were in general low and that amplification and deep deletion were the main mutation type. The expression and function of IL-17A and IL-17B in lung cancer are still not fully elucidated and require studies with larger sample sizes. The survival results revealed that IL-17C, IL-25 and IL-17F have prognostic roles in lung cancer. IL-17D was significantly decreased in lung cancer and was correlated with better OS. The interaction network and biological pathway analyses of the IL-17 family indicated that IL-17 family genes share functional associations with each other. These findings can provide a reference for further experimental studies to identify the molecular mechanism of IL-17D in lung cancer progression.

Nevertheless, some limitations exist in the present study. First, the correlation between the IL-17 gene family and OS within each subclass of clinical parameters, namely, pathologic $\mathrm{N}$ stage, pathologic $\mathrm{T}$ stage, and pathologic $\mathrm{M}$ stage, was not analysed due to data limitations. Second, the mutations and expression levels of IL-17 genes in lung cancer cells need to be validated in a future experimental study. In addition, future functional investigations are required to explore the underlying mechanisms of the IL-17 gene family in lung cancer development. In conclusion, in the present study, we performed the first comprehensive investigation of the IL-17 gene family in lung cancer, including gene mutations, mRNA expression levels, prognostic values and network pathway analysis. Although gene mutations and mRNA expression levels were abnormal in lung cancer patients, IL-17 family gene mutation rates were low in general, and only IL-17D was significantly decreased in lung cancer and was correlated with better OS. The expression and function of IL-17A and IL-17B in lung cancer are still not fully elucidated and require studies with larger sample sizes. Studies of IL-17C-F in lung cancer are limited. Therefore, more research attention should be given to the association between IL-17D and lung cancer progression to identify more effective therapeutic targets for lung cancer.

\section{Acknowledgements}

Not applicable.

\section{Funding}

The present work was supported by The Natural Science Foundation of Hubei Province (grant no. 2014CFA057) and
The Health and Planning Commission Fund of Hubei Province (grant no. WJ2017M098).

\section{Availability of data and materials}

The datasets generated and analyzed during the current study are available in The COSMIC database (http://cancer. sanger.ac.uk/cosmic), ONCOMINE gene expression array datasets (https://www.oncomine.org/), Kaplan-Meier plotter (http://www.kmplot.com/analysis/index), The cbio cancer genomics portal (http://www.cbioportal.org/), STRING database (http://string-db.org/) and Funrich (http://www. funrich.org).

\section{Authors' contributions}

YJ and TTL conceived and designed the experiments. TTL, JSF and ZLL prepared the figures and tables, and drafted and revised the manuscript. JJX, FW, GHY, QH, GRH, MFG, MZ, LMD and SFW prepared the figures and interpreted the data. All authors read and approved the manuscript and agreed to be accountable for all aspects of the research in ensuring that the accuracy or integrity of any part of the work were appropriately investigated and resolved.

\section{Ethics approval and consent to participate}

Not applicable.

\section{Patient consent for publication}

Not applicable.

\section{Competing interests}

The authors state that they have no competing interests

\section{References}

1. Siegel RL, Miller KD and Jemal A: Cancer statistics, 2018. CA Cancer J Clin 68: 7-30, 2018

2. Allemani C, Matsuda T, Di Carlo V, Harewood R, Matz M, Nikšić M, Bonaventure A, Valkov M, Johnson CJ, Estève J, et al: Global surveillance of trends in cancer survival 2000-14 (CONCORD-3): Analysis of individual records for 37513 025 patients diagnosed with one of 18 cancers from 322 population-based registries in 71 countries. Lancet 391: 1023-1075, 2018.

3. Wu F, Xu J, Huang Q, Han J, Duan L, Fan J, Lv Z, Guo M, Hu G, Chen L, et al: The role of interleukin-17 in lung cancer. Mediators Inflamm 2016: 8494079, 2016.

4. Zhang Q, Liu S, Ge D, Zhang Q, Xue Y, Xiong Z, Abdel-Mageed AB, Myers L, Hill SM, Rowan BG, et al: Interleukin-17 promotes formation and growth of prostate adenocarcinoma in mouse models. Cancer Res 72: 2589-2599, 2012.

5. Akbay EA, Koyama S, Liu Y, Dries R, Bufe LE, Silkes M, Alam MM, Magee DM, Jones R, Jinushi M, et al: Interleukin-17A promotes lung tumor progression through neutrophil attraction to tumor sites and mediating resistance to PD-1 blockade. J Thorac Oncol 12: 1268-1279, 2017.

6. Numasaki M, Fukushi J, Ono M, Narula SK, Zavodny PJ, Kudo T, Robbins PD, Tahara H and Lotze MT: Interleukin-17 promotes angiogenesis and tumor growth. Blood 101: 2620-2627, 2003.

7. Wang L, Yi T, Kortylewski M, Pardoll DM, Zeng D and Yu H: IL-17 can promote tumor growth through an IL-6-Stat3 signaling pathway. J Exp Med 206: 1457-1464, 2009. 
8. Kryczek I, Wei S, Szeliga W, Vatan L and Zou W: Endogenous IL-17 contributes to reduced tumor growth and metastasis. Blood 114: 357-359, 2009

9. Gu FM, Li QL, Gao Q, Jiang JH, Zhu K, Huang XY, Pan JF, Yan J, Hu JH, Wang Z, et al: IL-17 induces AKT-dependent IL-6/JAK2/STAT3 activation and tumor progression in hepatocellular carcinoma. Mol Cancer 10: 150, 2011.

10. Chen JG, Xia JC, Liang XT, Pan K, Wang W, Lv L, Zhao JJ, Wang QJ, Li YQ, Chen SP, et al: Intratumoral expression of IL-17 and its prognostic role in gastric adenocarcinoma patients. Int J Biol Sci 7: 53-60, 2011.

11. Huang CK, Yang CY, Jeng YM, Chen CL, Wu HH, Chang YC Ma C, Kuo WH, Chang KJ, Shew JY and Lee WH: Autocrine/paracrine mechanism of interleukin-17B receptor promotes breast tumorigenesis through NF- $\mathrm{kB}$-mediated antiapoptotic pathway. Oncogene 33: 2968-2977, 2014.

12. Wu HH, Hwang-Verslues WW, Lee WH, Huang CK, Wei PC, Chen CL, Shew JY, Lee EY, Jeng YM, Tien YW, et al: Targeting IL-17B-IL-17RB signaling with an anti-IL-17RB antibody blocks pancreatic cancer metastasis by silencing multiple chemokines. J Exp Med 212: 333-349, 2015.

13. Bie Q, Sun C, Gong A, Li C, Su Z, Zheng D, Ji X, Wu Y, Guo Q, Wang $S$ and $\mathrm{Xu} \mathrm{H}$ : Non-tumor tissue derived interleukin-17B activates IL-17RB/AKT/ $\beta$-catenin pathway to enhance the stemness of gastric cancer. Sci Rep 6: 25447, 2016.

14. Pfeifer P, Voss M, Wonnenberg B, Hellberg J, Seiler F, Lepper PM, Bischoff M, Langer F, Schäfers HJ, Menger MD, et al: IL-17C is a mediator of respiratory epithelial innate immune response. Am J Respir Cell Mol Biol 48: 415-421, 2013.

15. Jungnickel C, Schmidt LH, Bittigkoffer L, Wolf L, Wolf A, Ritzmann F,Kamyschnikow A, HerrC, Menger MD, SpiekerT, et al: IL-17C mediates the recruitment of tumor-associated neutrophils and lung tumor growth. Oncogene 36: 4182-4190, 2017.

16. Song X, Gao H, Lin Y, Yao Y, Zhu S, Wang J, Liu Y, Yao X, Meng G, Shen N, et al: Alterations in the microbiota drive interleukin-17C production from intestinal epithelial cells to promote tumorigenesis. Immunity 40: 140-152, 2014.

17. O'Sullivan T, Saddawi-Konefka R, Gross E, Tran M, Mayfield SP, Ikeda $\mathrm{H}$ and Bui JD: Interleukin-17D mediates tumor rejection through recruitment of natural killer cells. Cell Rep 7: 989-998, 2014.

18. Yin SY, Jian FY, Chen YH, Chien SC, Hsieh MC, Hsiao PW, Lee WH, Kuo YH and Yang NS: Induction of IL-25 secretion from tumour-associated fibroblasts suppresses mammary tumour metastasis. Nat Commun 7: 11311, 2016.

19. Jiang Z, Chen J, Du X, Cheng H, Wang X and Dong C: IL-25 blockade inhibits metastasis in breast cancer. Protein Cell 8: 191-201, 2017.

20. Furuta S, Jeng YM, Zhou L, Huang L, Kuhn I, Bissell MJ and Lee WH: IL-25 causes apoptosis of IL-25R-expressing breast cancer cells without toxicity to nonmalignant cells. Sci Transl Med 3: 78ra31, 2011

21. Luo Y, Yang Z, Su L, Shan J, Xu H, Xu Y, Liu L, Zhu W, Chen X, Liu C, et al: Non-CSCs nourish CSCs through interleukin-17E-mediated activation of NF- $\kappa$ B and JAK/STAT3 signaling in human hepatocellular carcinoma. Cancer Lett 375: 390-399, 2016.

22. Liu Y, Zhao X, Sun X, Li Y, Wang Z, Jiang J, Han H, Shen W, Corrigan CJ and Sun Y: Expression of IL-17A, E, and F and their receptors in human prostatic cancer: Comparison with benign prostatic hyperplasia. Prostate 75: 1844-1856, 2015.

23. Xie Y, Sheng W, Xiang J, Ye Z and Yang J: Interleukin-17F suppresses hepatocarcinoma cell growth via inhibition of tumor angiogenesis. Cancer Invest 28: 598-607, 2010.

24. Ding L, Hu EL, Xu YJ, Huang XF, Zhang DY, Li B, Hu QG, Ni YH and Hou YY: Serum IL-17F combined with VEGF as potential diagnostic biomarkers for oral squamous cell carcinoma. Tumour Biol 36: 2523-2529, 2015

25. Forbes SA, Beare D, Gunasekaran P, Leung K, Bindal N, Boutselakis H, Ding M, Bamford S, Cole C, Ward S, et al: COSMIC: Exploring the world's knowledge of somatic mutations in human cancer. Nucleic Acids Res 43 (Database Issue) D805-D811, 2015

26. Rhodes DR, Kalyana-Sundaram S, Mahavisno V, Varambally R, Yu J, Briggs BB, Anstet MJ, Kincead-Beal C, Kulkarni P, et al: Oncomine 3.0: Genes, pathways, and networks in a collection of 18,000 cancer gene expression profiles. Neoplasia 9: 166-180, 2007.

27. Győrffy B, Surowiak P, Budczies J and Lánczky A: Online survival analysis software to assess the prognostic value of biomarkers using transcriptomic data in non-small-cell lung cancer. PLoS One 8: e82241, 2013
28. Yu T, Jia W, An Q, Cao X and Xiao G: Bioinformatic analysis of GLI1 and related signaling pathways in chemosensitivity of gastric cancer. Med Sci Monit 24: 1847-1855, 2018.

29. Cerami E, Gao J, Dogrusoz U, Gross BE, Sumer SO, Aksoy BA, Jacobsen A, Byrne CJ, Heuer ML, Larsson E, et al: The cBio cancer genomics portal: An open platform for exploring multidimensional cancer genomics data. Cancer Discov 2: 401-404, 2012.

30. Szklarczyk D, Franceschini A, Kuhn M, Simonovic M, Roth A, Minguez P, Doerks T, Stark M, Muller J, Bork P, et al: The STRING database in 2011: Functional interaction networks of proteins, globally integrated and scored. Nucleic Acids Res 39 (Database Issue): D561-D568, 2011.

31. Pathan M, Keerthikumar S, Ang CS, Gangoda L, Quek CY, Williamson NA, Mouradov D, Sieber OM, Simpson RJ, Salim A, et al: FunRich: An open access standalone functional enrichment and interaction network analysis tool. Proteomics 15: 2597-2601, 2015

32. Cancer Genome Atlas Research Network: Comprehensive molecular profiling of lung adenocarcinoma. Nature 511: 543-550, 2014.

33. Beltran H, Prandi D, Mosquera JM, Benelli M, Puca L, Cyrta J, Marotz C, Giannopoulou E, Chakravarthi BV, Varambally S, et al: Divergent clonal evolution of castration-resistant neuroendocrine prostate cancer. Nat Med 22: 298-305, 2016.

34. Eirew P, Steif A, Khattra J, Ha G, Yap D, Farahani H, Gelmon K, Chia S, Mar C, Wan A, et al: Dynamics of genomic clones in breast cancer patient xenografts at single-cell resolution. Nature 518: 422-426, 2015.

35. Hou J, Aerts J, den Hamer B, van Ijcken W, den Bakker M, Riegman P, van der Leest C, van der Spek P, Foekens JA, Hoogsteden HC, et al: Gene expression-based classification of non-small cell lung carcinomas and survival prediction. PLoS One 5: e10312, 2010.

36. Beer DG, Kardia SL, Huang CC, Giordano TJ, Levin AM, Misek DE, Lin L, Chen G, Gharib TG, Thomas DG, et al: Gene-expression profiles predict survival of patients with lung adenocarcinoma. Nat Med 8: 816-824, 2002.

37. Garber ME, Troyanskaya OG, Schluens K, Petersen S, Thaesler Z, Pacyna-Gengelbach M, van de Rijn M, Rosen GD, Perou CM, Whyte RI, et al: Diversity of gene expression in adenocarcinoma of the lung. Proc Natl Acad Sci USA 98: 13784-13789, 2001

38. Selamat SA, Chung BS, Girard L, Zhang W, Zhang Y, Campan M, et al: Genome-scale analysis of DNA methylation in lung adenocarcinoma and integration with mRNA expression. Genome Res 22 (7): 1197-1211, 2012.

39. Landi MT, Dracheva T, Rotunno M, Figueroa JD, Liu H, Dasgupta A, Mann FE, Fukuoka J, Hames M, Bergen AW, et al: Gene expression signature of cigarette smoking and its role in lung adenocarcinoma development and survival. PLoS One 3: e1651, 2008.

40. Okayama H, Kohno T, Ishii Y, Shimada Y, Shiraishi K, Iwakawa R, Furuta K, Tsuta K, Shibata T, Yamamoto S, et al: Identification of genes upregulated in ALK-positive and EGFR/KRAS/ALK-negative lung adenocarcinomas. Cancer Res 72: 100-111, 2012.

41. Liu J, Lichtenberg T, Hoadley KA, Poisson LM, Lazar AJ, Cherniack AD, Kovatich AJ, Benz CC, Levine DA, Lee AV, et al: An integrated TCGA pan-cancer clinical data resource to drive high-quality survival outcome analytics. Cell 173: 400-416.e11, 2018.

42. Gaffen SL: Recent advances in the IL-17 cytokine family. Curr Opin Immunol 23: 613-619, 2011

43. Chen X, Wan J, Liu J, Xie W, Diao X, Xu J, Zhu B and Chen Z: Increased IL-17-producing cells correlate with poor survival and lymphangiogenesis in NSCLC patients. Lung Cancer 69: 348-354, 2010 .

44. Liu J, Duan Y, Cheng X, Chen X, Xie W, Long H, Lin Z and Zhu B: IL-17 is associated with poor prognosis and promotes angiogenesis via stimulating VEGF production of cancer cells in colorectal carcinoma. Biochem Biophys Res Commun 407: 348-354, 2011.

45. Lin Q, Xue L, Tian T, Zhang B, Guo L, Lin G, Chen Z, Fan K and $\mathrm{Gu}$ X: Prognostic value of serum IL-17 and VEGF levels in small cell lung cancer. Int J Biol Markers 30: e359-e363, 2015.

46. Pan B, Che D, Cao J, Shen J, Jin S, Zhou Y, Liu F, Gu K, Man Y, Shang L and Yu Y: Interleukin-17 levels correlate with poor prognosis and vascular endothelial growth factor concentration in the serum of patients with non-small cell lung cancer. Biomarkers 20: 232-239, 2015 
47. Wang XF, Zhu YT, Wang JJ, Zeng DX, Mu CY, Chen YB, Lei W, Zhu YH and Huang JA: The prognostic value of interleukin-17 in lung cancer: A systematic review with meta-analysis based on Chinese patients. PLoS One 12: e0185168, 2017.

48. Wei L, Wang H, Yang F, Ding Q and Zhao J: Interleukin-17 potently increases non-small cell lung cancer growth. Mol Med Rep 13: 1673-1680, 2016.

49. Pan B, Shen J, Cao J, Zhou Y, Shang L, Jin S, Cao S, Che D, Liu F and $\mathrm{Yu} \mathrm{Y}$ : Interleukin-17 promotes angiogenesis by stimulating VEGF production of cancer cells via the STAT3/GIV signaling pathway in non-small-cell lung cancer. Sci Rep 5: 16053, 2015.

50. Huang Q, Duan L, Qian X, Fan J, Lv Z, Zhang X, Han J, Wu F, Guo M, Hu G, et al: IL-17 promotes angiogenic factors IL-6, IL-8, and Vegf production via Stat1 in lung adenocarcinoma. Sci Rep 6: 36551, 2016.

51. Li Q, Han Y, Fei G, Guo Z, Ren T and Liu Z: IL-17 promoted metastasis of non-small-cell lung cancer cells. Immunol Lett 148: 144-150, 2012

52. Lu L, Pan K, Zheng HX, Li JJ, Qiu HJ, Zhao JJ, Weng DS, Pan QZ, Wang DD, Jiang SS, et al: IL-17A promotes immune cell recruitment in human esophageal cancers and the infiltrating dendritic cells represent a positive prognostic marker for patient survival. J Immunother 36: 451-458, 2013.

53. Punt S, van Vliet ME, Spaans VM, de Kroon CD, Fleuren GJ, Gorter A and Jordanova ES: FoxP3(+) and IL-17(+) cells are correlated with improved prognosis in cervical adenocarcinoma. Cancer Immunol Immunother 64: 745-753, 2015.

54. He Y, Du Y, Wei S, Shi J, Mei Z, Qian L, Chen Z and Jie Z IL-17A and IL-17F single nucleotide polymorphisms associated with lung cancer in Chinese population. Clin Respir J 11: 230-242, 2017.

55. Ma QY, Chen J, Wang SH, Wu N, Hao ZH and Chen XF: Interleukin 17A genetic variations and susceptibility to non-small cell lung cancer. APMIS 123: 194-198, 2015.

56. Kaabachi W, ben Amor A, Kaabachi S, Rafrafi A, Tizaoui K and Hamzaoui K: Interleukin-17A and $-17 \mathrm{~F}$ genes polymorphisms in lung cancer. Cytokine 66: 23-29, 2014.

57. Li Z, Liu Y, Cao D, Jiang M and Luo F: IL-17A and IL-17F polymorphisms and gastric cancer risk: A meta-analysis. Genet Mol Res 14: 7008-7017, 2015.

58. Wróbel T, Gębura K, Wysoczańska B, Jaźwiec B, Dobrzyńska O, Mazur G, Kuliczkowski K and Bogunia-Kubik K: IL-17F gene polymorphism is associated with susceptibility to acute myeloid leukemia. J Cancer Res Clin Oncol 140: 1551-1555, 2014

59. Omrane I, Baroudi O, Bougatef K, Mezlini A, Abidi A, Medimegh I, Stambouli N, Ayari H, Kourda N, Uhrhammer N, et al: Significant association between IL23R and IL17F polymorphisms and clinical features of colorectal cancer. Immunol Lett 158: 189-194, 2014.

60. Cheng S, Shao Z, Liu X, Guo L, Zhang X, Na Q, Chen X, Ma Y, Zheng J, Song B and Liu J: Interleukin 17A polymorphism elevates gene expression and is associated with increased risk of nonsmall cell lung cancer. DNA Cell Biol 34: 63-68, 2015.

61. Rožman P and Švajger U: The tolerogenic role of IFN- $\gamma$. Cytokine Growth Factor Rev 41: 40-53, 2018.

62. Xu C, Hao K, Yu L and Zhang X: Serum interleukin-17 as a diagnostic and prognostic marker for non-small cell lung cancer. Biomarkers 19: 287-290, 2014.
63. Xu B, Guenther JF, Pociask DA, Wang Y, Kolls JK, You Z, Chandrasekar B, Shan B, Sullivan DE and Morris GF: Promotion of lung tumor growth by interleukin-17. Am J Physiol Lung Cell Mol Physiol 307: L497-L508, 2014.

64. Li Y, Cao ZY, Sun B, Wang GY, Fu Z, Liu YM, Kong QF, Wang JH, Zhang Y, Xu XY and Li HL: Effects of IL-17A on the occurrence of lung adenocarcinoma. Cancer Biol Ther 12: 610-616, 2014.

65. Numasaki M, Watanabe M, Suzuki T, Takahashi H, Nakamura A McAllister F, Hishinuma T, Goto J, Lotze MT, Kolls JK and Sasaki H: IL-17 enhances the net angiogenic activity and in vivo growth of human non-small cell lung cancer in SCID mice through promoting CXCR-2-dependent angiogenesis. J Immunol 175: 6177-6189, 2005

66. Zhao C, Li Y, Zhang W, Zhao D, Ma L, Ma P, Yang F, Wang Y, Shu Y and Qiu W: IL17 induces NSCLC A549 cell proliferation via the upregulation of HMGA1, resulting in an increased cyclin D1 expression. Int J Oncol Mar 7, 2018. DOI: 10.3892/ijo.2018.4307.

67. Chen X, Xie Q, Cheng X, Diao X, Cheng Y, Liu J, Xie W, Chen Z and Zhu B: Role of interleukin-17 in lymphangiogenesis in non-small-cell lung cancer: Enhanced production of vascular endothelial growth factor $\mathrm{C}$ in non-small-cell lung carcinoma cells. Cancer Sci 101: 2384-2390, 2010.

68. You R, DeMayo FJ, Liu J, Cho SN, Burt BM, Creighton CJ, Casal RF, Lazarus DR, Lu W, Tung HY, et al: IL17A regulates tumor latency and metastasis in lung adeno and squamous SQ.2b and AD.1 cancer. Cancer Immunol Res 6: 645-657, 2018

69. Gu K, Li MM, Shen J, Liu F, Cao JY, Jin S and Yu Y: Interleukin-17-induced EMT promotes lung cancer cell migration and invasion via NF- $\mathrm{kB} / \mathrm{ZEB} 1$ signal pathway. Am J Cancer Res 5: 1169-1179, 2015.

70. Kulig P, Burkhard S, Mikita-Geoffroy J, Croxford AL, Hövelmeyer N, Gyülvészi G, Gorzelanny C, Waisman A, Borsig L and Becher B: IL17A-mediated endothelial breach promotes metastasis formation. Cancer Immunol Res 4: 26-32, 2016.

71. Chang SH, Mirabolfathinejad SG, Katta H, Cumpian AM, Gong L, Caetano MS, Moghaddam SJ and Dong C: T helper 17 cells play a critical pathogenic role in lung cancer. Proc Natl Acad Sci USA 111: 5664-5669, 2014.

72. Liu L, Ge D, Ma L, Mei J, Liu S, Zhang Q, Ren F, Liao H, Pu Q, Wang $\mathrm{T}$ and You Z: Interleukin-17 and prostaglandin E2 are involved in formation of an M2 macrophage-dominant microenvironment in lung cancer. J Thorac Oncol 7: 1091-1100, 2012.

73. Yang YF, Lee YC, Lo S, Chung YN, Hsieh YC, Chiu WC and Yuan SF: A positive feedback loop of IL-17B-IL-17RB activates ERK $/ \beta$-catenin to promote lung cancer metastasis. Cancer Lett 422: 44-55, 2018.

74. Liao C, Yu ZB, Meng G, Wang L, Liu QY, Chen LT, Feng SS, Tu HB, Li YF and Bai L: Association between Th17-related cytokines and risk of non-small cell lung cancer among patients with or without chronic obstructive pulmonary disease. Cancer 121 (Suppl 17): S3122-S3129, 2015.

This work is licensed under a Creative Commons Attribution-NonCommercial-NoDerivatives 4.0 International (CC BY-NC-ND 4.0) License. 